\title{
Maximum phonation time in the pulmonary function assessment
}

Universidade de Pernambuco - UPE, Programa de Iniciação Científica, Petrolina, Pernambuco, Brasil. Universidade de Pernambuco - UPE, Programa de pós Graduação em Hebiatria, Recife, Pernambuco, Brasil.

Universidade Federal de Pernambuco UFPE, Recife, Pernambuco Brasil.

Programa Associado de pós Graduação em Educação Física, UPE/UFPB, Recife, Pernambuco, Brasil.

\section{Conflict of interests: Nonexistent}

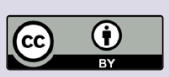

Received on: July 29, 2020 Accepted on: March 17, 2021

Corresponding address:

Marco Aurélio de Valois Correia Junior

Rua Luiz Guimarães, 411 - 301 A,

Poço da Panela

CEP: 52061-160 - Recife, Pernambuco Brasil

E-mail:marcovalois@gmail.com

\author{
Edvania Gomes Henrique Moreno' \\ https://orcid.org/0000-0002-8195-4468 \\ Bianca Teixeira Calassa ${ }^{1}$ \\ https://orcid.org/0000-0003-0779-6585 \\ Daniela Vitoria Silva Oliveira ${ }^{1}$ \\ https://orcid.org/0000-0002-0702-6663 \\ Maylanne Iris Nascimento Silva ${ }^{1}$ \\ https://orcid.org/0000-0002-5991-9287 \\ Laienne Carla Barbosa de Barros Albuquerque ${ }^{2}$ \\ https://orcid.org/0000-0001-6612-5269 \\ Ricardo de Freitas-Dias ${ }^{2}$ \\ https://orcid.org/0000-0003-4846-9951 \\ Bruno Rafael Vieira Souza Silva $a^{3,4}$ \\ https://orcid.org/0000-0002-6140-6990 \\ Rodrigo Capatto de Araújo $0^{3,4}$ \\ https://orcid.org/0000-0002-6399-3201 \\ Eduarda Lubambo Costa ${ }^{3}$ \\ https://orcid.org/0000-0001-9549-4426 \\ Emília Chagas Costa ${ }^{3}$ \\ https://orcid.org/0000-0002-7664-5994 \\ Marco Aurélio de Valois Correia Junior 2,4 \\ https://orcid.org/0000-0003-0386-5256
}

\section{ABSTRACT}

Purpose: to evaluate the reliability of the maximum phonation time (MPT) and Vital Capacity intra and inter-examiner, by means of the single-breath counting test (CT) and the sustained /a/ phoneme, and the slow vital capacity (SVC).

Methods: a reliability study carried out in three groups of healthy individuals, each group with 30 volunteers, allocated according to age. SVC was measured using a spirometer, while the MPT was assessed by the phoneme /a/ and CT. The data were analyzed using SPSS version 20.0. Initially, descriptive statistics were used and for data reliability, the intraclass correlation coefficient (ICC).

Results: the Intraclass Correlation Coefficients (ICC) were considered excellent, with significant results above 0.92 for SVC and greater than 0.79 for CT and phoneme /a/. Regarding the inter-examiner evaluation, the ICCs were also significant for both SVC with values greater than 0.96 , and for CT and the phoneme /a/ with values greater than 0.85. The error inherent in the technique was assessed using the standard error of the measurement for intra and inter-examiner analyses with values ranging from 1.79 to 3.29 for phoneme /a/, 3.20 to 6.58 for CT and 65, 05 to 206.73 for SVCml.

Conclusion: phonation techniques with the phoneme /a/ and CT, as well as SVC, have an excellent reliability, due to intra and inter-examiner agreement measures.

Keywords: Phonation; Vital Capacity; Spirometry; Health Assessment 


\section{INTRODUCTION}

Slow Vital Capacity (SVC) is an important measurement of pulmonary function, assessed by means of equipments such as ventilometers and spirometers, with the objective of assisting in the prevention, diagnosis and evaluation of the clinical evolution of respiratory diseases. The subject is asked to take a deep breath and then exhale as much air as possible. The importance of trying to obtain a good reliability between the SVC repetitions is evidenced in the evaluations of the changes that can happen in the clinical scenario, for example, in the monitoring of diseases and / or interventions. However, it is a relatively expensive procedure, which requires the presence of a specialist and whose devices are not always available in the service units, resulting in the need to seek cheaper and alternative methods, in order to make this assessment possible ${ }^{1-6}$.

The Maximum Phonation Time (MPT) has been proposed as an alternative method for the evaluation of SVC-7, in which the evaluator measures the patient's ability to maintain the emission or count, for the maximum possible time during a single expiration. As it integrates parts of two systems (respiratory and phonatory), the MPT constitutes an evaluative parameter of pulmonary measurements and indicates the efficiency of the existing coordination between the respiratory and phonatory systems. Thus, the duration of phonation in an intact larynx theoretically reflects the lung function of the individual ${ }^{8,9}$.

The main attraction of this technique is the fact that it is a low-cost, non-invasive method, easy to perform and that uses only the voice for evaluation, and can be done in any environment, such as clinics, hospitals and in the individual's own residence ${ }^{5-7}$. In addition, as it is a technique that makes it possible to evaluate the emission of the voice in a quantitative way, it is possible to develop studies that compare pre- and post-treatment values and in different populations.

In this context, when assessing the reliability of MPT in comparison to established methods of pulmonary function evaluation, it is important to verify its consistency, that is, how much can be reproduced without changing its results, over time, when used in different circumstances or by different examiners ${ }^{10}$. In view of the above, the present study aimed to assess the reliability of MPT with the slow vital capacity, intra and interexaminer, through the single-breath counting test, the sustained /a/ phoneme and the slow vital capacity, in healthy individuals of different age groups.

\section{METHODS}

This is a reliability study, developed at the Petrolina campus of the University of Pernambuco (UPE), Petrolina, Pernambuco, Brazil and at the Elderly Living Center in the same city, approved by the Ethics and Research Committee with Human Beings at the University of Pernambuco - UPE, Brazil, (protocol number 478,571, CAAE: 20222613.5.0000.5207).

The research was carried out with healthy individuals (who did not have chronic respiratory diseases) of both sexes, aged between 18 and 85 years, subdivided into three groups: young adults (18-30 years), adults (31-59 years) and the elderly (over 60 years old) - in which the first two groups were formed by students and employees of the UPE and the third group by volunteers from the elderly center in the city where the research was carried out.

Individuals who reported influenza, cold or asthma attacks during the week of collection, pregnant women, participants in singing classes and / or those who play wind instruments and complaints or diagnosed with dysphonia were excluded from the study ${ }^{5}$. Also excluded were volunteers who did not know how to count or were unable to understand the techniques and those who during the interview reported inflammation, infection or injury to the upper respiratory tract ${ }^{5,6}$.

Initially, personal data were collected - age, sex, height and total body mass (TBM), since such measures influence vital capacity2 ${ }^{2}$. To assess TBM and height, a digital scale with a precision of 50 grams (G-TECH, Pernambuco, Brazil) and a scientific stadiometer with a precision of $0.5 \mathrm{~cm}$ (Sanny, São Bernardo do Campo, Brazil) were used, according to the standardization from the International Society for the Advancement of Kinanthropometry (ISAK) ${ }^{11}$.

The SVC maneuver (SVCml) was performed by a digital spirometer (MicroQuark ${ }^{\circledR}$ spirometer, Cosmed - Italy), according to the American Thoracic Society ATS standards ${ }^{3,12}$. All participants were instructed to perform a maximum inhalation, followed by maximum exhalation slowly, using a mouthpiece, with the nostrils occluded by a nose clip ${ }^{3,12}$. To calculate the SVC relative (SVCml / Kg) to the ideal TBM of each individual, the following formulas were applied: TBM female $=45+$ $0.93 \times$ (height -152.4 ) and TBM male $=50+0.91 \times$ (height - 152.4) ${ }^{13}$.

The maximum phonation time was assessed using the phoneme $/ \mathrm{a} /$ and the single-breath counting test (CT) technique, both performed in the original language of the evaluated population (Portuguese). The method 
with the phoneme /a/ was chosen because the vowel in question is central, open and detects the smallest changes in the glottal level, and can be used for any voice test. CT, on the other hand, allows the evaluator to qualitatively and quantitatively check respiratory and phonatory control during linked speech ${ }^{5,6}$.

In order to evaluate the phoneme /a/, the participants were instructed to inhale as much air as possible and during the exhalation start the sustained pronunciation of the phoneme /a/ for as long as possible, in a single exhalation. For $\mathrm{CT}$, participants were instructed to inhale as much air as possible and during exhalation they should start counting in ascending order, starting from numeral 01 (one) to the largest number they could achieve in a single exhalation. Both techniques (phoneme / a / and CT) were performed through comfortable exhalation, maintaining the frequency and intensity of habitual phonation. To measure time, a digital stopwatch (KENKO ${ }^{\circledR}$ stopwatch, model KK-2808 - Brazil) was used.

The SVC and MPT maneuvers (phoneme / a / and CT) were applied by two evaluators in separate rooms, with no physical or visual contact between them, in order not to influence the test conducted by another examiner ${ }^{14}$. All participants received verbal and visual instructions on how to perform the maneuvers. The best measurement was chosen from three attempts made for each technique ${ }^{5-7,15-19}$, which were performed according to a standardized rest interval of three minutes between the maneuvers and five minutes between the performance of the different techniques.

The order of choice of techniques was carried out randomly, as well as the order of the examiner's assessment (simple draw), both in the assessment and in the reassessment. All of these procedures were repeated 15 days after the first exam. The tests would be interrupted if the participant showed signs of respiratory distress during the procedure, but it was not necessary to interrupt any exam.

The data were entered and double-checked using Microsoft Excel 2013 software and analyzed using the Statistical Package for the Social Sciences - SPSS ${ }^{\circledR}$, version 20.0 for Windows (IBM, Chicago, IL, USA). To assess the normality of the data, the Shapiro Wilk test was used. To obtain the mean and standard deviation (SD) of the parametric variables, descriptive Statistics was used. In order to verify the test-retest agreement intra and inter-examiner, the Intraclass Correlation Coefficients (ICC) for the MPT maneuvers were analyzed, with values greater than 0.75 being considered as excellent ${ }^{20}$. The ICC values found were used to calculate the standard error of measurement (SEM) and the minimum difference detectable (MDD) with 95\% confidence. The standard error of measurement was calculated from the formula: SEM $=S D \sqrt{ }(1-I C C)$, where SD is the standard deviation of the mean at the beginning of the study; and the ICC value was derived from the test-retest agreement and the MDD by the equation: $\mathrm{MDD}_{95}=1.96 * \mathrm{SEM}_{95}$ $* \sqrt{2^{21-23}}$. SEM and MDD values are expressed in the same unit as the measured measures.

\section{RESULTS}

The study began with 107 healthy individuals (aged 18-85 years), 17 of whom were excluded: nine volunteers (four from the adult group and five from the elderly group) for not showing up for the reassessment and 8 from the elderly group for not being able to perform the SVC technique. Thus, 90 volunteers $(30 \%$ men) participated in the research, 30 from the group of young adults (13\% men), 30 adults (40\% men) and 30 elderly ( $37 \%$ men).

The general characteristics of the sample such as age, ideal TBM, height, SVC, CT and phoneme / a / are shown in Table 1. 
Table 1. General characteristics of the sample, according to the subdivision of the groups

\begin{tabular}{|c|c|c|c|c|}
\hline Variables & $\begin{array}{l}\text { General } \\
\mathrm{N}=90\end{array}$ & $\begin{array}{c}\text { Young Adult } \\
n=30\end{array}$ & $\begin{array}{l}\text { Adult } \\
n=30\end{array}$ & $\begin{array}{c}\text { Elderly } \\
n=30\end{array}$ \\
\hline Age (years) & $43.85 \pm 22.20$ & $20.70 \pm 1.68$ & $39.23 \pm 9.25$ & $71.60 \pm 6.8$ \\
\hline TBM $(\mathrm{kg})$ & $64.53 \pm 12.87$ & $59.10 \pm 10.37$ & $71.73 \pm 13.54$ & $62.10 \pm 12.36$ \\
\hline TBM Ideal (kg) & $55.04 \pm 7.46$ & $54.80 \pm 6.74$ & $57.78 \pm 7.85$ & $52.01 \pm 6.79$ \\
\hline Height (m) & $1.62 \pm 0.07$ & $1.63 \pm 0.06$ & $1.64 \pm 0.07$ & $1.58 \pm 0.06$ \\
\hline$S V C_{m l}$ first week - Ev. 1 & $3078.55 \pm 744.41$ & $3513.00 \pm 726.57$ & $3503.66 \pm 650.48$ & $2219.00 \pm 728.02$ \\
\hline SVC $_{\mathrm{ml}}$ first week - Ev. 2 & $3125.22 \pm 735.49$ & $3607.33 \pm 743.43$ & $3489.66 \pm 642.69$ & $2278.66 \pm 740.21$ \\
\hline $\mathrm{SVC}_{\mathrm{ml}}$ second week - Ev. 1 & $2629.33 \pm 834.85$ & $3593.33 \pm 787.65$ & $2147.33 \pm 628.61$ & $2147.33 \pm 672.15$ \\
\hline SVC $_{\mathrm{ml}}$ second week - Ev. 2 & $3050.55 \pm 784.46$ & $3587.67 \pm 736.48$ & $3413.66 \pm 629.23$ & $2150.33 \pm 668.14$ \\
\hline$S V C_{m / k g}$ first week - Ev. 1 & $55.63 \pm 11.46$ & $63.43 \pm 9.22$ & $60.99 \pm 09.86$ & $42.47 \pm 12.15$ \\
\hline$S V C_{m / k g}$ first week - Ev. 2 & $56.46 \pm 11.32$ & $65.06 \pm 8.94$ & $60.71 \pm 09.35$ & $43.64 \pm 12.37$ \\
\hline$S C_{m l / k g}$ second week - Ev. 1 & $55.37 \pm 12.56$ & $64.97 \pm 11.05$ & $60.00 \pm 08.97$ & $41.16 \pm 11.33$ \\
\hline$S C_{m / k g}$ second week - Ev. 2 & $55.15 \pm 12.40$ & $64.83 \pm 9.77$ & $59.45 \pm 09.59$ & $41.16 \pm 10.87$ \\
\hline CT first week - Ev. 1 (count*) & $53.30 \pm 9.74$ & $59.87 \pm 15.36$ & $57.93 \pm 15.89$ & $42.10 \pm 20.21$ \\
\hline CT first week - Ev. 2 (count) & $54.51 \pm 11.06$ & $61.00 \pm 14.09$ & $60.80 \pm 16.04$ & $41.73 \pm 19.54$ \\
\hline CT second week - Ev. 1 (count) & $56.87 \pm 11.27$ & $63.17 \pm 16.82$ & $63.60 \pm 14.92$ & $43.86 \pm 20.80$ \\
\hline CT second week - Ev. 2 (count) & $57.35 \pm 11.61$ & $64.63 \pm 16.82$ & $63.46 \pm 15.41$ & $43.96 \pm 20.31$ \\
\hline Phoneme /a/ first week - Ev. 1 (s) & $24.03 \pm 1.77$ & $25.54 \pm 8.72$ & $24.46 \pm 05.94$ & $22.08 \pm 10.00$ \\
\hline Phoneme /a/ first week - Ev. 2(s) & $25.48 \pm 1.81$ & $26.74 \pm 10.16$ & $26.30 \pm 07.23$ & $23.40 \pm 09.18$ \\
\hline Phoneme /a/ second week - Ev. 1(s) & $23.84 \pm 2.26$ & $26.10 \pm 9.09$ & $23.84 \pm 06.53$ & $21.57 \pm 09.60$ \\
\hline Phoneme /a/ second week - Ev. 2 (s) & $25.09 \pm 1.88$ & $27.20 \pm 9.31$ & $24.49 \pm 06.50$ & $23.58 \pm 10.02$ \\
\hline
\end{tabular}

Captions: TBM = Total Body Mass; SVC = Slow Vital Capacity; CT = Single-breath counting test. Retest $=$ After 15 days $(\mathrm{s})=$ seconds. ${ }^{*}$ Count $=$ maximum count reached in an ascending order, starting from the numeral 1 (one) up to the largest number they could reach in a single expiration.

The ICCs found for the intra-examiner variables were considered excellent, ranging from 0.92 to 0.99 for $\mathrm{SVC}_{\mathrm{ml}}$, and from 0.86 to 0.94 and 0.79 to 0.96 for CT and phoneme /a/ respectively (Table 2 ). Regarding the inter-examiner evaluation, the ICCs were also considered excellent for both $\mathrm{SVC}_{\mathrm{ml}}(0.96-0.99)$ and CT (0.93-0.97) and phoneme /a/ (0.85-0, 95).

The standard error measure (SEM) values of the intra-examiner ranged from 2.00 to 3.09 for the phoneme /a/, 3.99 to 6.58 for CT, 68.22 to 206.73 for $\mathrm{SVC}_{\mathrm{ml}}$ and 1,29 to 3.91 for $\mathrm{SVC}_{\mathrm{m} / \mathrm{kg}}$. The minimum difference detectable (MDD) ranged from 5.54 to 8.85 for / a /, 11.07 to 18.24 for CT, 189.10 to 573.02 for $\mathrm{SVCml}$ and from 3.56 to 10.84 for $\mathrm{SVC}_{\mathrm{m} / \mathrm{kg}}$ (Table 2). In the analysis of the results between the inter-examiner test and retest, the SEM ranged from 1.79 to 3.29 for / a I, 3.20 to 4.29 for CT, 65.05 to 153.54 for $\mathrm{SVC}_{\mathrm{ml}}$ and 1 , 17 to 2.75 for $\mathrm{SVC}_{\mathrm{m} / \mathrm{kg}}$ (Table 3). 
Table 2. Intra-examiner reliability using the Intraclass Correlation Coefficients, standard error of measurement and the minimum difference detectable

\begin{tabular}{lccccccccc}
\hline & \multicolumn{3}{c}{ Young Adult } & \multicolumn{4}{c}{ Adult } & \multicolumn{3}{c}{ Elderly } \\
\cline { 2 - 10 } & ICC (CI 95\%) & SEM & MDD & ICC (CI 95\%) & SEM & MDD & ICC (CI 95\%) & SEM & MDD \\
\hline Evaluator 1 & & & & & & & & & \\
Phoneme /a/ (s) & $0.91(0.80-0.95)$ & 2.67 & 7.41 & $0.79(0.56-0.89)$ & 2.73 & 7.56 & $0.96(0.92-0.98)$ & 2.00 & 5.54 \\
CT (count*) & $0.92(0.82-0.96)$ & 4.42 & 12.27 & $0.92(0.84-0.96)$ & 4.41 & 12.22 & $0.89(0.78-0.95)$ & 6.58 & 18.24 \\
SVC ml & $0.95(0.89-0.98)$ & 162.46 & 450.33 & $0.99(0.98-0.99)$ & 68.22 & 189.10 & $0.98(0.96-0.99)$ & 97.67 & 270.74 \\
SVC ml/Kg & $0.91(0.82-0.96)$ & 2.72 & 7.54 & $0.98(0.96-0.99)$ & 1.29 & 3.56 & $0.98(0.95-0.99)$ & 1.88 & 5.22 \\
\hline Evaluator 2 & & & & & & & & & \\
Phoneme /a/ (s) & $0.91(0.81-0.96)$ & 3.05 & 8.45 & $0.87(0.72-0.94)$ & 2.62 & 7.25 & $0.89(0.762-0.95)$ & 3.09 & 8.55 \\
CT (count $\left.{ }^{\star}\right)$ & $0.86(0.70-0.93)$ & 5.31 & 14.71 & $0.94(0.87-0.97)$ & 3.99 & 11.07 & $0.92(0.82-0.96)$ & 5.63 & 15.60 \\
SVC ml & $0.97(0.4-0.99)$ & 124.40 & 344.82 & $0.97(0.94-0.99)$ & 111.32 & 380.56 & $0.92(0.83-0.96)$ & 206.73 & 573.02 \\
SVC mI/Kg & $0.95(0.89-0.97)$ & 2.08 & 5.76 & $0.96(0.92-0.98)$ & 1.87 & 5.18 & $0.90(0.79-0.95)$ & 3.91 & 10.84 \\
\hline
\end{tabular}

Captions: CT = single-breath counting test; SVC = Slow Vital Capacity; ICC = Intraclass Correlation Coefficient; SEM = Standard Error of the Measure;

$\mathrm{MDD}=$ minimum difference detectable $; \mathrm{Cl}=$ Confidence Interval; Retest = after 15 days; $(\mathrm{s})=$ seconds; ${ }^{*}$ Count $=$ maximum count reached in an ascending order, starting from the numeral 1 (one) up to the largest number they could reach in a single expiration. SEM and MDD values are expressed in the same measurement unit. All ICC values showed $p<0.001$.

Table 3. Inter-examiner reliability using the Intraclass Correlation Coefficients and the standard error of the measurement

\begin{tabular}{lcccccc}
\hline & \multicolumn{2}{c}{ Young Adult } & \multicolumn{2}{c}{ Adult } & \multicolumn{2}{c}{ Elderly } \\
\cline { 2 - 7 } & ICC (CI 95\%) & SEM & ICC (CI 95\%) & SEM & ICC (CI 95\%) & SEM \\
\hline Test & & & & & & \\
Phoneme /a/ (s) & $0.91(0.82-0.96)$ & 2.58 & $0.85(0.69-0.93)$ & 2.29 & $0.89(0.77-0.95)$ & 3.29 \\
CT (count*) & $0.95(0.91-0.98)$ & 3.26 & $0.93(0.85-0.96)$ & 4.29 & $0.97(0.93-0.98)$ & 3.73 \\
SVC ml & $0.99(0.97-0.99)$ & 79.60 & $0.99(0.98-0.99)$ & 65.05 & $0.97(0.94-0.99)$ & 126.10 \\
SVC ml/Kg & $0.97(0.94-0.99)$ & 1.51 & $0.99(0.97-0.99)$ & 1.17 & $0.96(0.92-0.98)$ & 2.43 \\
\hline Retest & & & & & & \\
Phoneme /a/ (s) & $0.95(0.91-0.98)$ & 1.93 & $0.92(0.84-0.96)$ & 1.79 & $0.94(0.88-0.97)$ & 2.29 \\
CT (count*) & $0.95(0.89-0.97)$ & 3.91 & $0.95(0.90-0.98)$ & 3.20 & $0.96(0.99-0.98)$ & 4.11 \\
SVC ml & $0.96(0.92-0.98)$ & 153.54 & $0.98(0.96-0.99)$ & 81.96 & $0.98(0.95-0.99)$ & 99.70 \\
SVC ml/Kg & $0.94(0.87-0.97)$ & 2.75 & $0.98(0.95-0.99)$ & 1.36 & $0.97(0.94-0.99)$ & 1.90 \\
\hline
\end{tabular}

Captions: $\mathrm{CT}=$ single-breath counting test; SVC = Slow Vital Capacity; ICC = Intraclass Correlation Coefficient; SEM = Standard Error of the Measure;

$\mathrm{Cl}=$ Confidence Interval; Retest = after 15 days; (s) = seconds; * Count = maximum count reached in an ascending order, starting from the numeral 1 (one) up to the largest number they could reach in a single expiration. SEM values are expressed in the same measurement unit. All ICC values showed $p<0.001$.

\section{DISCUSSION}

The results of the present study showed that both the slow vital capacity and the single-breath counting test (CT) technique and the sustained /a/ phoneme are reliable intra and inter-examiner in young adults, healthy adults and elderly. In addition, the values of the standard error of the measurement (SEM) and the minimum difference detectable (MDD) found can objectively guide the interpretation of the results so that the data are not confused with the inherent errors of the technique.

In clinical practice, the measurement of SVC is important, as it makes it possible to effectively assess pulmonary functionality and integrity of the airways, aiding in the , diagnosis and evaluation of the effectiveness of treatments involving pulmonary capacity ${ }^{1-6}$. As the individual ages, there is a progressive reduction in functional lung capacity and an observed decrease in SVC between the ages of 20 and 70 years $^{24}$. For this reason, the assessment of reliability in this research was separated into different age groups. The possibility of applying other methods that do not depend on the use of specific equipment to estimate vital capacity for the assessment of patients' clinical evolution would be useful for health professionals ${ }^{1-6}$. Recently, this evidence has been corroborated by researchers ${ }^{5-7,9}$ 
who have made important contributions, especially with regard to the use of MPT as an alternative method of assessing lung function, compared with spirometry and/or ventilometry ${ }^{5-7}$.

The association between SVC and MPT has already been reported in the scientific literature both in healthy individuals ${ }^{5}$ and in hospitalized patients ${ }^{6,7}$, however, little has been explored about reliability in healthy individuals. Lima et al. ${ }^{5}$ studied healthy adults of both sexes and found a moderate correlation for the phonemes / a / and / s / and weak for the phoneme / z / and CT ( $r=0.420,0.442,0.399$ and 0.279; $p<0.05$, respectively). In contrast, Palmeira et al. ${ }^{6}$ and Cardoso et al. ${ }^{7}$ found a strong positive correlation between CT and SVC when they evaluated hospitalized individuals $(r=0.760 \text {, with } p<0.0001)^{6}$ and $(r=0.856$, with $p$ $<0.01)^{7}$. This difference found between healthy ${ }^{5}$ and hospitalized ${ }^{6,7}$ can be explained because the selection made by the authors ${ }^{5}$ of the group of individuals without lung disease had similar ages and lung conditions, which led to small variations in the measurements and thus, weak correlations ${ }^{5-7}$.

Although CT is presented in some studies as an alternative in the assessment of $\mathrm{SVC}^{6,23}$, the present study does not aim to replace spirometry, but to add to the understanding of pathophysiological information. Escóssio et al. ${ }^{23}$ evaluated the accuracy of the singlebreath counting test to determine the slow vital capacity and suggested, with good psychometric results, a count of up to 21 to find values below $20 \mathrm{ml} / \mathrm{kg}$ of SVC. These same authors ${ }^{23}$ described that this technique could be used in screening for referral to more specific tests of respiratory function. This research opens up future possibilities for the study of children who would not be able to perform the spirometry technique, or even patients who are unable to perform the spirometry technique properly, due to tiredness, or maneuvering difficulties. It is also a precursor to possibilities of multicentric comparisons involving other languages and other people with different racial characteristics, in addition to presenting some clinical applicability in calls by teleconference and by patients who need remote monitoring, such as patients affected by the current pandemic.

The choice of healthy individuals in this research occurred because subjects without pulmonary pathologies do not present changes in lung function in short periods between one and two weeks, and a possible change in values would be inherent in the technique and not in a respiratory change ${ }^{3}$. Therefore, repeatability and/or reliability must be the first step in the use and dissemination of a technique ${ }^{9,10}$, especially when proposing an alternative to established methods. The results described here suggest that phonation techniques with the phoneme /a/ and single-breath counting test, when compared with the SVC obtained through spirometry, have similar concordances, whether performed by the same or by different examiners, on different days. These results are favorable for the use of MPT techniques and open several possibilities for the evaluation of the pulmonary function, especially were specific equipment is unavaliable.

The values found for MPT and CT in the present study refer to healthy individuals with no pulmonary involvement. Normative values $8,14-18,25-27$ for adolescent audiences very close to those presented in the current survey (greater than 20 seconds and counting above 50) had already been reported by Lima et al. ${ }^{25}$. In contrast, Cielo et al. ${ }^{26}$. found indicators for 20-second men and 14-second women without counting values. In the present study, as expected ${ }^{22}$, the elderly population was shown to have lower values.

A counted value of $51.85 \pm 15.1$ was reported for the population of Brazilian adolescents and young adults, being $55.07 \pm 15.7$ in males and $50.49 \pm 14.7$ in females ${ }^{25}$. Latronico and Rasulo ${ }^{28}$, in a review study, explain that a rough estimate of the SVC could be made by the single-breath counting test in neuromuscular individuals unable to count to 20 , they would have a vital capacity around 15 to $18 \mathrm{ml} / \mathrm{kg}$, and techniques are indicated intervention in the quest to improve these results. Despite this finding, the researchers did not explain how they arrived at these values and did not refer to $i^{28}$. A very interesting discussion about a survey by a Brazilian group was recently published in a letter to the editor ${ }^{29}$. In it, researcher Yossef Aelony, comments on the importance of the technique in patients with contagious diseases such as tuberculosis and discusses a publication 1962, where young males, probably Caucasian, counted in English up to $100+20$.

Some differences can be found in the design of other studies, in relation to this research, mainly with regard to the collection method and the comparison with the SVC. Englert et al..$^{14}$ evaluated the phoneme /a/ agreement, measured by three evaluators simultaneously, the first (being only one of the examiners with experience on the area) used an acoustic analysis program and the other two evaluators used a digital timer. Three measurements were taken in a single day and found that the MPT is reliable regardless of the 
form of extraction and the experience of the evaluator. The present study differs from the previous research ${ }^{14}$, since it assessed the reliability of the MPT independently by two evaluators who performed the techniques (phoneme / a / sustained and CT), without any physical or visual contact between them, performed on different days and in individuals of different age groups.

Speyer et al. ${ }^{8}$ evaluated the MPT agreement and variability in dysphonic individuals compared to a control group of healthy people, by recording the phoneme /a/ by a single evaluator. These recordings were made five times and evaluated by five examiners in three different days ${ }^{8}$. The authors concluded that the MPT is a reliable measure in the evaluation of phonation and that only a test performed in a single day, by an evaluator offers reliable measurements ${ }^{8}$. The current research adds scientific knowledge that the phoneme / a / and the CT technique performed at the time of the examination (without the need for recording) by two examiners, compared with the SVC, show excellent agreement. A recent study ${ }^{23}$ using a methodology similar to this also found an excellent relibility (ICC = 0.976 with $p<0.005$ ) in hospitalized individuals, when evaluated by the same researcher on the same day.

This research offers an important contribution when it presents SEM and MDD values for the phoneme /a/ and single-breath counting test, comparing the SVC, especially because these values can serve as a basis to know if there was an objective change in the values, resulting from a worsening caused by some disease or if it was just a measurement error. This investigation showed that the extreme values of the intra-examiner SEM varied for the phoneme /a/ (2.62-2.73) and for the single-breath counting test (3.99-4.41) and the inter-examiner SEM of the phoneme /a/ ( 1.79-2.29) and single-breath counting test (3.20-4.29). If, during the evaluation and reassessment of lung function in healthy individuals, there are changes below the limits presented, these will be considered only an error of measurement.

The MDD was determined to know the minimum amount of change needed in the tests to be considered relevant and to verify the difference between the two measurements performed. Thus, the results can guide health professionals in the sense of identifying real changes between assessments. Considering the values of the MDD for the evaluation and reassessment sessions, the changes that occurred to be considered would have to be greater than 8.45 for the phoneme /a/ and 14.71 for TC of the young people, 7.56 for $/ \mathrm{a} /$ and
12.22 for the CT of adults and 8.55 for / a / and 18.24 for the CT of the elderly.

A possible limitation of the research was the time interval between measurements, since the elderly population included in the study needs a longer rest time for physiological reasons, being necessary to increase the rest time by 15 seconds $5,7,8,14$ to three minutes, standardized for all the age groups. In addition, as the research was carried out with healthy individuals, generalizations for patients with pulmonary pathologies or hospitalized patients should be used as a reference and applied with great caution. On the other hand, the research results lead to several possibilities for future research into the assessment of lung function comparing different phonation techniques and their clinical applicability in different populations, controlled by age but not by sex.

\section{CONCLUSION}

The present study showed that sustained /a/ phoneme techniques and single-breath counting test in relation to SVC, showed an excellent reliability in the intra and inter-examiner methods, in healthy young individuals, adults and the elderly.

\section{ACKNOWLEDGMENTS}

The authors would like to thank Christopher Storey for helping in reviewing English. This study was financed in part by the Coordenação de Aperfeiçoamento de Pessoal de Nível Superior - Brasil (CAPES) - Finance Code 001.

\section{REFERENCES}

1. Barros ARG, Pires MB, Raposo NMF. Importância da capacidade vital lenta na detecção de obstrução das vias aéreas. J Bras Pneumol. 2013;39(3):317-22.

2. Pereira CAC, Duarte $A A O$, Gimenez A, Soares MR. Comparison between reference values for FVC, FEV1, and FEV1/FVC ratio in white adults in Brazil and those suggested by the Global Lung Function Initiative 2012. J bras pneumol. 2014;40(4):397-402 .

3. Miller MR, Hankinson J, Brusasco V, Burgos F, Casaburi R, Coates A et al. Standardisation of spirometry. Eur Respir J. 2005;26(2):319-38.

4. Heckman EJ, O'Connor GT. Pulmonary function tests for diagnosing lung disease. JAMA. 2015;313(22):2278-9. 
5. Lima DCB, Palmeira AC, Costa EC, Mesquita FOS, Andrade FMD, Correia Júnior MAV. Correlation between slow vital capacity and the maximum phonation time in healthy adults. Rev. CEFAC. 2014;16(2):592-7.

6. Palmeira AC, Araújo RC, Escossio AL, Sarinho SW, Rizzo JA, Andrade FMD et al. Use of the technique of counting numbers as a predictor of slow vital capacity in hospitalized individuals. Rev. CEFAC. 2015;17(2):559-66.

7. Cardoso NFB, Araújo RC, Palmeira AC, Dias RF, França EET, Andrade FMD et al. Correlação entre o tempo máximo de fonação e a capacidade vital lenta em indivíduos hospitalizados. ASSOBRAFIR Ciênc. 2013;4(3):9-17.

8. Speyer R, Bogaardt HCA, Passos VLP, Roodenburg NPHD, Zumach A, Heijnen MAM et al. Maximum phonation time: variability and reliability. $\mathrm{J}$ Voice. 2010;24(3):281-4.

9. Ali SS, O'Connell C, Kass L, Graff G. Single-breath counting: a pilot study of a novel technique for measuring pulmonary function in children. Am J Emerg Med. 2011;29(1):33-6.

10. Martins GA. Sobre confiabilidade e validade. RBGN. 2006;8(20):1-12.

11. Marfell-Jones M, Olds T, Stewart A, Carter L. International standards for anthropometric assessment ISAK. Potchefstroom, South Africa, 2006.

12. García-Ríoa $F$, Calle $M$, Burgos $F$, Casan $P$, Campo F del, Galdiz JB et al. Espirometría. Arch Bronconeumol. 2013;49(9):388-401.

13. Brower RG, Matthay MA, Morris A, Schoenfeld $\mathrm{D}$, Thompson $\mathrm{T}$, Wheeler A. Ventilation with lower tidal volumes as compared with traditional tidal volumes for acute lung injury and the acute respiratory distress syndrome. The acute respiratory distress syndrome network. $\mathrm{N}$ Engl J Med. 2000;342(18):1301-8.

14. Englert M, Mesquita LG, Azevedo R. Comparison of methods to extract the maximum phonation duration in individuals without vocal complaints. Rev. CEFAC. 2014;16(5):1615-20.

15. Miglioranzi SH, Cielo CA, Siqueira MA. Capacidade vital e tempos máximos de fonação de /e/ áfono e de /s/ em mulheres adultas. Rev. CEFAC. 2012;14(1):97-103.

16. Cielo CA, Lima JPM, Gonçalves BFT, Christmann MK. Relations between /s/ and /z/ and between /e/ and voiceless/e/. Rev. CEFAC. 2013;15(5):1308-15.
17. Cielo CA, Christmann MK, Scherer TM, Hoffmann CF. Adapted air flow and phonic coefficients of future voice professionals. Rev. CEFAC. 2014;16(2):546-53.

18. Christmann MK, Scherer TM, Cielo CA, Hoffmann CF. Maximum phonation time of future professional voice users. Rev. CEFAC. 2013;15(3):622-30.

19. Silva PNC, Jardim JR, Souza GMC, Hyland ME, Nascimento AO. Adaptação cultural e reprodutibilidade do Questionário para Problemas Respiratórios em pacientes portadores de DPOC no Brasil. J Bras Pneumol. 2012;38(3):339-45.

20. Fleiss JL. Measuring nominal scale agreement among many raters. Psychol Bull. 1971;76:378-82.

21. Tucci HT, Martins J, Sposito GC, Camarini PMF. Closed Kinetic Chain Upper Extremity Stability test (CKCUES test): a reliability study in persons with and without shoulder impingement syndrome. BMC Musculoskeletal Disorders. 2014;15(1):1-9.

22. Stratford PW. Getting more from the literature: estimating the standard error of measurement from reliability studies. Physiother Can. 2004;56(1):27-30.

23. Escóssio AL, Araujo RC, Olive N, Costa EC, Rizzo JA, Sarinho ESC et al. Accuracy of singlebreath counting test to determine slow vital capacity in hospitalized patients. Rev. CEFAC. 2019;21(2):e2119.

24. Ren W-Y, LI L, Zhao R-Y, Zhu L. Age-associated changes in pulmonary function: a comparison of pulmonary function parameters in healthy young adults and the elderly living in Shanghai. Chin Med J. 2012;125(17):3064-8.

25. Lima DCB de, Palmeira AC, Costa EC, Mesquita FOC, Andrade FMD, Correia Junior MAV. Correlation between slow vital capacity and the maximum phonation time in healthy adults. Rev. CEFAC. 2014;16(2):592-7.

26. Cielo CA, Casarin MT. Sons fricativos surdos. Rev. CEFAC. 2008;10(3):352-8.

27. Steffen LM, Moschetti MB, Steffen N, Hanayama EM. Paralisia unilateral de prega vocal: associação e correlação entre tempos máximos de fonação, posição e ângulo de afastamento. Rev. Bras. Otorrinolaringol. 2004;70(4):450-5.

28. Latronico N, Rasulo FA. Presentation and management of ICU myopathy and neuropathy. Curr Opin Crit Care. 2010;16(2):123-7.

29. Aelony Y, Correia Junior MAV. Correlation between slow vital capacity and the maximum phonation time in healthy adults. Rev. CEFAC. 2016;18(5):1031-4. 


\section{ERRATUM}

In the article, "Maximum phonation time in the pulmonary function assessment", with DOI number: $10.1590 / 1982-0216 / 20212349720$, published in the journal Revista Cefac 2021;23(4):e9720, in the author affiliation (page 1):

\section{Where it was:}

Marco Aurélio de Valois Correia Junior ${ }^{2,3,4}$ and

${ }^{4}$ Universidade Federal da Paraíba - UFPB, Programa de pós Graduação Associado em Educação Física, Recife, Pernambuco, Brasil.

\section{Read:}

Marco Aurélio de Valois Correia Junior ${ }^{2,4}$ and

${ }^{4}$ Programa Associado de pós Graduação em Educação Física, UPE/UFPB, Recife, Pernambuco, Brasil. 